\title{
BMJ Open Cross-sectional survey on job satisfaction and its associated factors among doctors in tertiary public hospitals in Shanghai, China
}

Jiazhen Liu, ${ }^{1}$ Wenya Yu, ${ }^{2}$ Tao Ding, ${ }^{2}$ Meina Li, ${ }^{2}$ Lulu Zhang ${ }^{\circledR 2}$

To cite: Liu J, Yu W, Ding T, et al. Cross-sectional survey on job satisfaction and its associated factors among doctors in tertiary public hospitals in Shanghai, China. BMJ Open 2019:9:e023823. doi:10.1136/ bmjopen-2018-023823

- Prepublication history and additional material for this paper are available online. To view these files, please visit the journal online (http://dx.doi. org/10.1136/bmjopen-2018023823).

Received 25 April 2018 Revised 18 December 2018 Accepted 25 January 2019

Check for updates

(c) Author(s) (or their employer(s)) 2019. Re-use permitted under CC BY-NC. No commercial re-use. See rights and permissions. Published by BMJ.

${ }^{1}$ Shanghai Information Center for Health, Shanghai Municipal Commission of Health and Family Planning, Shanghai,

China

${ }^{2}$ College of Military Health Service Management, Second Military Medical University, Shanghai, China

Correspondence to Professor Lulu Zhang; zllrmit@aliyun.com

\section{ABSTRACT}

Objectives Doctors in public hospitals in China face considerable pressure and excessive workloads, which are likely to predispose them to job dissatisfaction. We explored the job satisfaction of doctors and examined the influence of diverse sociodemographic characteristics.

Design This was a cross-sectional study.

Setting Eleven tertiary public hospitals in Shanghai, China.

Participants The questionnaire was designed based on the fifth National Health Service General Research, which was based on the Minnesota Satisfaction Questionnaire. Questionnaires were administered to 897 doctors randomly (using random number tables) and 730 were returned completed (response rate $=81.4 \%$ ). Doctors who volunteered and provided informed, written consent participated.

Primary outcome measures The dependent variable was doctors' job satisfaction.

Results Statistical analyses were conducted using SPSS and SAS. Overall, $64.8 \%$ of participants were dissatisfied with their jobs. Factors that were statistically significant to doctors' job satisfaction in the univariate analysis were entered into the logistic regression analysis, including doctors' professional title, department, work hours, work requirements (reflected as the number of patients they diagnosed and treated monthly), life and work stress, and the types of patients that doctors treated or expected to treat. The results of the logistic regression analysis suggested that doctors' job satisfaction was related to their professional title, types of patients that doctors treated or expected to treat, as well as their work stress. Conclusions There is an urgent need for public hospitals in China to establish a more reasonable promotion and management system for doctors, encourage patients to accept the two-way referral, pay more attention to lessexperienced staff and help doctors release their work stress.

\section{BACKGROUND}

Work-related problems of doctors are growing global concerns, especially doctors' job satisfaction. ${ }^{1}$ Job satisfaction comprises issues such as burnout, ${ }^{2}{ }^{3}$ mental health, ${ }^{4}$ work-family balance $^{5}$ and quality of care. ${ }^{6}$ Several studies

\section{Strengths and limitations of this study}

- We tried to suggest ways to improve doctors' job satisfaction and promote becoming a doctor in China.

- We provided a valuable reference for others interested in doctors' job satisfaction and working conditions in China.

- We provided quantitative data concerning doctors working conditions.

- Our research findings are only representative of doctors in tertiary A public hospitals in China.

- Income or income-workload balance was not explored in this study, which is a major limitation.

have explored job satisfaction, including its diverse dimensions ${ }^{2}$; its influencing factors ${ }^{7}$; and interrelationships between burnout, ${ }^{3}$ work stress, ${ }^{8} 9$ mental health ${ }^{4}$ and job satisfaction among doctors, nurses, and medical staff in diverse departments, regions and countries. ${ }^{10}$ Several studies in different countries have also indicated that income and income-workload balance are related to doctors' job satisfaction. ${ }^{11-13}$

Scholars from different countries such as the USA, the UK and Germany have tried to deal with problems concerning job dissatisfaction. ${ }^{14-16}$ For example, scholars in the USA noted that workload, work meaningfulness, relational needs, tolerance and risk-taking attitudes were associated with job satisfaction. ${ }^{14}$ Researchers in the UKindicated that whether physicians can fully use their training was a key factor influencing their job satisfaction. ${ }^{15}$ Scholars in Germany paid more attention to foreign-national physicians and suggested that human relations and social status were related to their job satisfaction. ${ }^{16}$ In addition, job characteristics ${ }^{910} 17-21$ and personal factors ${ }^{22-25}$ have been found to affect job satisfaction. 
Further, doctors themselves pay great attention to job satisfaction. Doctors worldwide fight for their own rights to improve job satisfaction, working condition, professional accomplishmentsand career development. For example, doctors in Poland ${ }^{26}$ and the Czech Republic ${ }^{27}$ have had conflicts with their respective governments regarding overwork. Fortunately, doctors in many countries and regions have succeeded in this fight, which ultimately improves their job satisfaction, work efficiency and care quality. ${ }^{28}$

Moreover, healthcare reform is a vital component of doctors' job satisfaction and working conditions, and China is no exception. In Chinese healthcare reform, the government pays considerable attention to reducing medication costs. ${ }^{29}$ Hospitals are expected to sell drugs to patients without adding a $15 \%$ profit, which may decrease the hospital's income. ${ }^{30}$ Other policies such as controlling medication fees per visit and the cost of medical insurance have reduced doctors' decision-making power. Consequently, hospital management may force doctors to work overtime to augment or maintain hospital income if there is not enough government compensation. ${ }^{31}$ Moreover, doctors had to change their behaviours to fulfil hospital income indicators. In China, over 4.5 million doctors are under increasing pressures to see more patients, meet increased administrative requirements, and keep up with government regulations. ${ }^{32}$ Moreover, the lives of doctors are threatened in hospitals owing to poor doctor-patient relationships. ${ }^{33}$ As doctors are overworked, underpaid and under threat, some scholars have wondered who will be the next doctors in China. ${ }^{34}$

Therefore, the main purpose of this study was to suggest ways to promote the development of more doctors in China and improve the condition of doctors. We determined what factors affect doctors' job satisfaction in China and provide practical recommendations to improve Chinese doctors' job satisfaction and working conditions.

\section{METHODS}

\section{Participants}

Between June 18 and September 27, 2013, a cross-sectional survey of doctors' job satisfaction was conducted in Shanghai, China. Using random number tables, we selected eleven tertiary public hospitals in Shanghai. Questionnaires were administered to 1000 doctors in these hospitals. All participants were also chosen through random number tables, which were based on doctors' job number. Of the 1000 participants, 897 were willing to participate and 103 doctors were excluded from this study because of their unwillingness to participate. Of these, 730 were returned complete (valid response rate $=81.4 \%$ ). Doctors who volunteered and provided informed, written consent participated. Researchers addressed doctors' queries and doubts regarding the questionnaire as needed.

\section{Instrument development and validation}

The questionnaire was designed to examine doctors' working conditions and job satisfaction. The questionnaire was designed based on the fifth National Health Service General Research by the National Health and Family Planning Commission of the People's Republic of China. ${ }^{35}$ The general survey of the National Health Service included job satisfaction of medical staff. It was a rigorously developed instrument, based on the well-known and widely used Minnesota Satisfaction Questionnaire. ${ }^{36}$ Its content validity was validated through an expert panel discussion, which included five experts. To determine the internal consistency of this questionnaire, Cronbach's $\alpha$ coefficient was calculated, which was 0.65 . The Kaiser-Meyer-Olkin test was used as a screening test for factorability, which was 0.703 $(\mathrm{p}<0.001)$, indicating acceptable validity.

We collected data on sociodemographic variables such as age, sex, education level, position, professional title and department. Positions comprised directors, doctors, researchers and unspecified staff. The unspecified staff members were doctoral students studying and working in these hospitals. There were some structured questions about types of patients, including types of patients that doctors thought should be treated in different healthcare institutions, doctors' satisfaction with the types of patients they were treating, and what types of patients they expected to treat. In addition, we asked about doctors' work time, life stress, work stress and the sources of work stress. The sources of work stress included work intensity, long hours, patients' lofty expectations, job risks, poor patient-doctor relationships, poor colleague relationships, competition for promotion, poor social evaluations and societal misunderstandings. Work intensity reflected the quantum of doctors' work, which was mainly evaluated by the number of patients that doctors diagnosed and treated (including surgery). Poor social evaluations reflected doctors' reputation among patients, which considered doctors' professional abilities and personal characteristics. We also asked doctors to rate their relationships with patients and evaluate patients' medical expenses. Questions about working and life stress, and doctor-patient relationships were measured using a 5-point Likert scale (not respectful, relatively not respectful, moderate, relatively respectful and very respectful). Doctors' job satisfaction was the dependent variable in this study. Because job satisfaction and dissatisfaction were evaluated from multiple aspects, doctors had to make an evaluation of their job based on their work time, life stress, work stress and the sources of work stress. Based on the definition by Gothe $e t a l,{ }^{37}$ if the individual is happy with their job after considering all the above factors, they could evaluate their job as satisfactory; otherwise, they could evaluate it as dissatisfactory.

\section{Statistical analyses}

All data were entered into Epidata V.3.1 and analysed using SPSS V.19.0 and SAS V.8.0. Sociodemographic data were described using frequencies and percentages. $\chi^{2}$ tests were employed to test the differences in job satisfaction among 
Table 1 Participants' personal and job characteristics

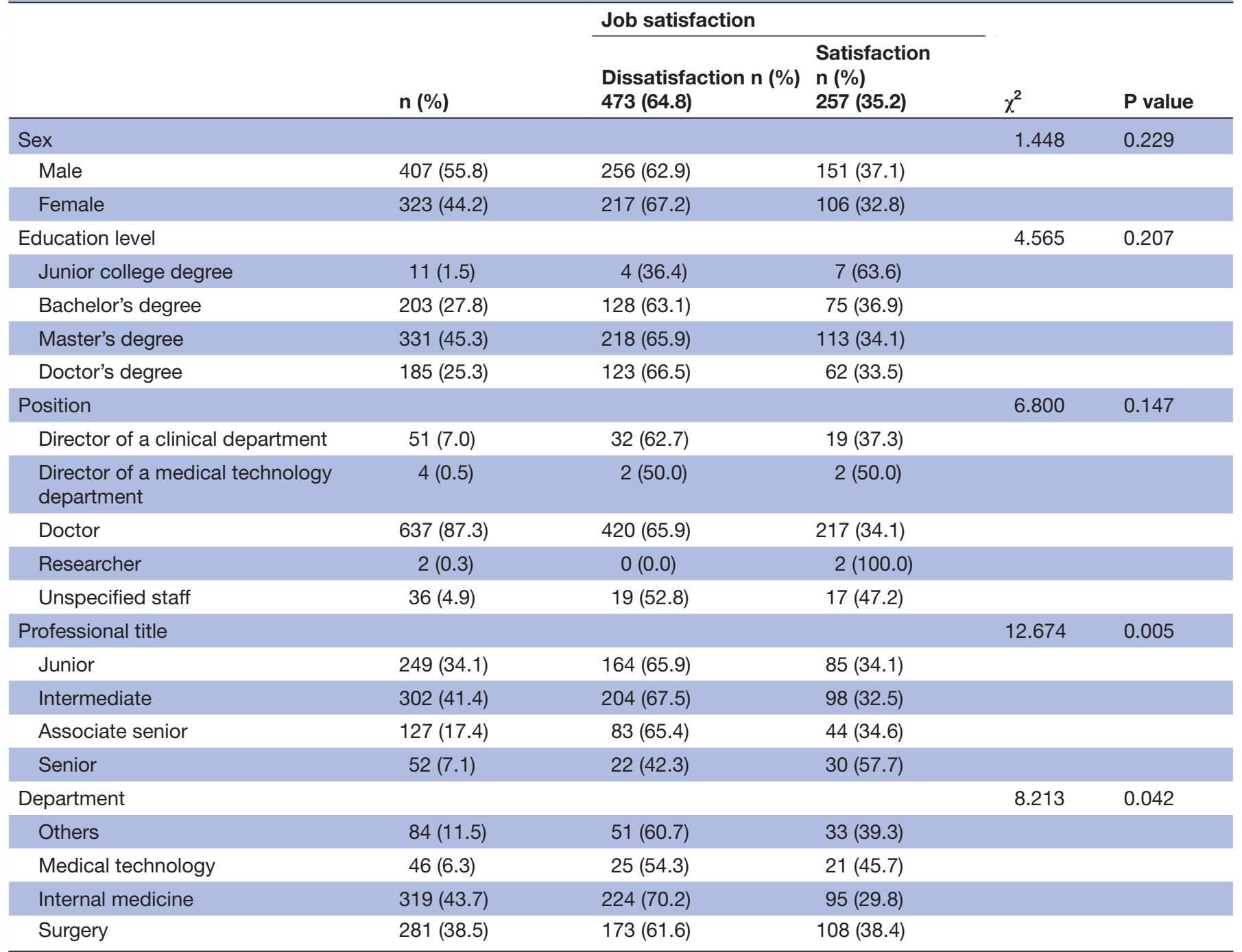

doctors with different personal characteristics and other factors. A binary logistic regression analysis was further used to verify the influence of factors on doctors' job satisfaction. In the logistic regression analysis, the dependent variable was doctors' job satisfaction. Independent variables entered into the logistic regression analysis were based on the univariate analysis results that were all significantly related to doctors' job satisfaction. We employed the stepwise selection method, with inclusion criteria of 0.10 and exclusion criteria of 0.15 . We also employed a multicollinearity analysis to test collinearity. All tests were two-tailed and $\mathrm{p}<0.05$ was considered significant.

\section{Patient and public involvement}

We declare that no patients or public were involved in this study.

\section{RESULTS}

Characteristics, working condition and job satisfaction

Overall, $64.8 \%$ of participants were dissatisfied with their jobs. Participants' personal and job characteristics are shown in table 1.
Working conditions and participants' job satisfaction are shown in table 2 . Nearly $88 \%$ of the participants worked more than 40 hours a week. It was found that $85 \%$ of the doctors could basically meet the hospitals' working requirements, which were reflected as the number of patients they diagnosed and treated monthly. Most reported work and life stress, which had increased in the last year, and was due to working intensity, long hours and job risks. In addition, about one-third of doctors reported that their departments organised a community health lecture, and more than half of the departments participated in a volunteer medical consultation.

Considering the types of patients, participants believed patients with difficult-to-diagnose diseases, serious diseases and rare diseases should seek medical treatment in tertiary A hospitals. Most participants treated patients with common diseases, chronic diseases and those seeking medicine; only about half of them were satisfied with the type of patients they met, which differed from whom they were expecting to treat more often. Participants felt that many of these patients should seek medical 
Table 2 Working conditions and participants' job satisfaction

\section{Job satisfaction}

\begin{tabular}{|c|c|c|c|c|c|}
\hline & \multirow[b]{2}{*}{ n (\%) } & \multicolumn{2}{|l|}{ Job satisfaction } & \multirow[b]{2}{*}{$\chi^{2}$} & \multirow[b]{2}{*}{$P$ value } \\
\hline & & $\begin{array}{l}\text { Dissatisfaction n (\%) } \\
473(64.8)\end{array}$ & $\begin{array}{l}\text { Satisfaction } \\
\text { n (\%) } \\
257(35.2)\end{array}$ & & \\
\hline \multicolumn{4}{|l|}{ Work hours per week (hours) } & 16.935 & 0.002 \\
\hline$\leq 40$ & $90(12.3)$ & $44(48.9)$ & $46(51.1)$ & & \\
\hline $41-55$ & $277(37.9)$ & $185(66.8)$ & $92(33.2)$ & & \\
\hline $56-70$ & $282(38.6)$ & $190(67.4)$ & $92(32.6)$ & & \\
\hline $71-85$ & $56(7.7)$ & $42(75.0)$ & $14(25.0)$ & & \\
\hline$\geq 86$ & $25(3.4)$ & $12(48.0)$ & $13(52.0)$ & & \\
\hline \multicolumn{4}{|c|}{ Whether the work within working hours met hospital requirements } & 13.846 & 0.008 \\
\hline Can & $253(34.7)$ & $161(63.6)$ & $92(36.4)$ & & \\
\hline Mostly can & $367(50.3)$ & $224(61.0)$ & $143(39.0)$ & & \\
\hline Mostly cannot & $68(9.3)$ & 55 (80.9) & $13(19.1)$ & & \\
\hline Cannot & $20(2.7)$ & $15(75.0)$ & $5(25.0)$ & & \\
\hline Hard to say & $22(3.0)$ & 18 (81.8) & $4(18.2)$ & & \\
\hline \multicolumn{4}{|l|}{ Life stress } & 20.524 & $<0.0001$ \\
\hline Very light & $2(0.3)$ & $2(100.0)$ & $0(0.0)$ & & \\
\hline Relatively light & $6(0.8)$ & $3(50.0)$ & $3(50.0)$ & & \\
\hline Moderate & $153(21.0)$ & $80(52.3)$ & $73(47.7)$ & & \\
\hline Relatively great & 362 (49.6) & 234 (64.6) & $128(35.4)$ & & \\
\hline Very great & 207 (28.4) & $154(74.4)$ & 53 (25.6) & & \\
\hline \multicolumn{6}{|l|}{ Work stress } \\
\hline Very light & $0(0.0)$ & $0(0.0)$ & $0(0.0)$ & 39.135 & $<0.0001$ \\
\hline Relatively light & $3(0.4)$ & $0(0.0)$ & $3(100.0)$ & & \\
\hline Moderate & $88(12.1)$ & 37 (42.0) & $51(58.0)$ & & \\
\hline Relatively great & $358(49.0)$ & $225(62.8)$ & $133(37.2)$ & & \\
\hline Very great & 281 (38.5) & $211(75.1)$ & 70 (24.9) & & \\
\hline \multicolumn{4}{|c|}{ Whether current work stress increased compared with that in the past year } & 20.777 & $<0.0001$ \\
\hline Yes & $576(78.9)$ & $392(68.1)$ & $184(31.9)$ & & \\
\hline No & $73(10.0)$ & $30(41.1)$ & $43(58.9)$ & & \\
\hline Hard to say & $81(11.1)$ & $51(63.0)$ & $30(37.0)$ & & \\
\hline \multicolumn{6}{|l|}{ Reflection of great work stress } \\
\hline Work intensity & $480(65.8)$ & $341(71.0)$ & $139(29.0)$ & 23.979 & $<0.0001$ \\
\hline Long work time & $421(57.7)$ & $303(72.0)$ & $118(28.0)$ & 22.459 & $<0.0001$ \\
\hline $\begin{array}{l}\text { High expectations of } \\
\text { patients }\end{array}$ & $341(46.7)$ & $230(67.4)$ & $111(32.6)$ & 1.976 & 0.160 \\
\hline High job risks & $403(55.2)$ & $291(72.2)$ & $112(27.8)$ & 21.678 & $<0.0001$ \\
\hline $\begin{array}{l}\text { Poor patient-doctor } \\
\text { relationships }\end{array}$ & $396(54.2)$ & 277 (69.9) & $119(30.1)$ & 10.083 & 0.001 \\
\hline $\begin{array}{l}\text { Poor colleague } \\
\text { relationships }\end{array}$ & $42(5.8)$ & $33(78.6)$ & $9(21.4)$ & 3.708 & 0.054 \\
\hline $\begin{array}{l}\text { Fierce competition for } \\
\text { promotion }\end{array}$ & $310(42.5)$ & $223(71.9)$ & $87(28.1)$ & 12.045 & 0.001 \\
\hline Poor social evaluations & $205(28.1)$ & $162(79.0)$ & $43(21.0)$ & 25.303 & $<0.0001$ \\
\hline Social misunderstandings & $302(41.8)$ & $208(68.2)$ & $97(31.8)$ & 2.658 & 0.103 \\
\hline \multicolumn{4}{|c|}{ Whether departments once organised a community health lecture } & 1.542 & 0.214 \\
\hline
\end{tabular}




\begin{tabular}{|c|c|c|c|c|c|}
\hline & \multirow[b]{2}{*}{ n (\%) } & \multicolumn{2}{|l|}{ Job satisfaction } & \multirow[b]{2}{*}{$\chi^{2}$} & \multirow[b]{2}{*}{$P$ value } \\
\hline & & $\begin{array}{l}\text { Dissatisfaction n (\%) } \\
473(64.8)\end{array}$ & $\begin{array}{l}\text { Satisfaction } \\
\text { n (\%) } \\
257(35.2)\end{array}$ & & \\
\hline No & $465(63.7)$ & $309(66.5)$ & $156(33.5)$ & & \\
\hline Yes & 265 (36.3) & $164(61.9)$ & $101(38.1)$ & & \\
\hline Yes & $412(56.4)$ & $264(64.1)$ & $148(35.9)$ & & \\
\hline
\end{tabular}

treatment in the community health system, especially patients with common and chronic diseases, and those seeking medicines. Further, about half of the participants thought patients' medical expenses were costly. Finally, less than half of the participants felt respected by their patients (table 3 ).

\section{Univariate analysis of job satisfaction and its influencing factors}

Using $\chi^{2}$ tests, the relationships between job satisfaction and other factors were examined. Results indicated that several factors significantly influenced doctors' job satisfaction (all $\mathrm{p}$ values $<0.05$ ), including the following: professional title $\left(\chi^{2}=12.674\right)$, department $\left(\chi^{2}=8.213\right)$, work hours every week $\left(\chi^{2}=16.935\right)$, whether the work within working hours met hospital requirements $\left(\chi^{2}=\right.$ 13.846), life stress $\left(\chi^{2}=20.524\right)$, work stress $\left(\chi^{2}=39.135\right)$, whether current work stress increased compared with that in the past year $\left(\chi^{2}=20.777\right)$, whether work intensity reflected work stress $\left(\chi^{2}=23.979\right)$, whether working long hours reflected work stress $\left(\chi^{2}=22.459\right)$, whether high jobs risks reflected work stress $(\chi 2=21.678)$, whether a poor patient-doctor relationship reflected work stress $\left(\chi^{2}\right.$ $=1.083)$, whether competition for promotion reflected work stress $\left(\chi^{2}=12.045\right)$, whether a poor social evaluation reflected work stress $\left(\chi^{2}=25.303\right)$, whether patients should seek medical treatment in tertiary A hospitals $\left(\chi^{2}=4.209\right)$, whether patients seeking medicine were the most common type doctors treated $\left(\chi^{2}=16.713\right)$, whether doctors were satisfied with the type of patients they treated $\left(\chi^{2}=49.153\right)$, whether patients with common diseases were the population doctors expected $\left(\chi^{2}=\right.$ 7.987), whether patients with acute diseases were the population doctors expected $\left(\chi^{2}=7.830\right)$, and the extent patients respected doctors $\left(\chi^{2}=44.764\right)$ (tables 1-3).

\section{Logistic regression analysis of job satisfaction and its influencing factors}

Variables that were significant to doctors' job satisfaction in the univariate analysis were included in the binary logistic regression analysis. To testify the collinearity among variables, a multicollinearity analysis was conducted. If tolerance is $<0.1$ or the variance inflation factor is $>5$, collinearity exists. The multicollinearity analysis indicated that collinearity did not exist (online supplementary table $1)$.

As shown in table 4, nine factors were entered into the logistic regression model. Doctors who were satisfied with the types of patients they treated were more likely to be satisfied with their job compared with those who were not satisfied. Doctors who did not consider work intensity or poor social evaluation as reflective of their work stress had more job satisfaction than did their counterparts. Doctors who felt moderate work stress felt more satisfied with their job compared with those with great work stress. Doctors who had an expectation of treating patients with common diseases were more satisfied with their jobs. Finally, doctors with senior professional titles were more satisfied with their job compared with doctors with lowerlevel titles.

\section{DISCUSSION}

Doctors' job satisfaction was influenced by their professional title, patient composition and work stress. Some factors like department, work hours, patients' respect and life stress were also related to doctors' job satisfaction.

First, unlike some studies in other countries and regions, demographic characteristics (eg, sex and education background) were not influencing factors of job satisfaction. $^{38} 39$ Only doctors' professional title played a role, which was supported by other studies in China ${ }^{5}$ and Canada. ${ }^{40}$ Junior doctors were less satisfied with their job, which may be attributed to many other factors. Because doctors' income was related to their professional title, ${ }^{41}$ the annual income of junior doctors was always lower than that of senior doctors. However, studies have proposed that income positively influences doctors' job satisfaction. $^{252042}$ In addition, a study in the UK noted that young staff may fail to fully use their training, which could foster low satisfaction. ${ }^{15}$ This can also be explained by opportunities to use one's abilities and personal accomplishments during daily work, which were other aspects impeding young staff from enjoying job satisfaction. ${ }^{7}$ Moreover, junior doctors in China face additional difficulties, including an unfair promotion system. ${ }^{43}$ Furthermore, the new policy about specialist standardisation 
Table 3 Patient-related issues and job satisfaction

\begin{tabular}{lllll} 
& \multicolumn{2}{l}{ Job satisfaction } & & \\
\cline { 2 - 3 } & Dissatisfaction $n$ & Satisfaction & & \\
$(\%)$ & $n(\%)$ & $\chi^{2}$ & P value
\end{tabular}

Which types of patients should seek medical treatment in tertiary A public hospitals (MCQ*)

\begin{tabular}{|c|c|c|c|c|c|}
\hline All types & $301(41.2)$ & $182(60.5)$ & $119(39.5)$ & 4.209 & 0.040 \\
\hline Chronic diseases & $165(22.6)$ & $98(59.4)$ & $67(40.6)$ & 2.726 & 0.099 \\
\hline Rare diseases & $389(53.3)$ & $258(66.3)$ & $131(33.7)$ & 0.854 & 0.355 \\
\hline Common diseases & $171(23.4)$ & $105(61.4)$ & $66(38.6)$ & 1.126 & 0.289 \\
\hline Acute diseases & $321(44.0)$ & $211(65.7)$ & $110(34.3)$ & 0.221 & 0.638 \\
\hline Difficult-to-diagnose diseases & $484(66.3)$ & $321(66.3)$ & $163(33.7)$ & 1.470 & 0.225 \\
\hline Rehabilitation & $71(9.7)$ & $45(63.4)$ & $26(36.6)$ & 0.069 & 0.793 \\
\hline Serious diseases & $453(62.1)$ & $294(64.9)$ & $159(35.1)$ & 0.006 & 0.939 \\
\hline \multicolumn{6}{|c|}{ Which types of patients doctors treated in most work hours (MCQ*) } \\
\hline Chronic diseases & $496(67.9)$ & $321(64.7)$ & $175(35.3)$ & 0.004 & 0.950 \\
\hline Rare diseases & $82(11.2)$ & $46(56.1)$ & $36(43.9)$ & 3.063 & 0.080 \\
\hline Common diseases & $606(83.0)$ & $399(65.8)$ & $207(34.2)$ & 1.715 & 0.190 \\
\hline Acute diseases & $140(19.2)$ & $87(62.1)$ & $53(37.9)$ & 0.534 & 0.465 \\
\hline Difficult-to-diagnose diseases & $190(26.0)$ & $114(60.1)$ & $76(40.0)$ & 2.588 & 0.108 \\
\hline Rehabilitation & $81(11.1)$ & $52(64.2)$ & $29(35.8)$ & 0.014 & 0.905 \\
\hline Serious diseases & $150(20.5)$ & $87(58.0)$ & $63(42.0)$ & 3.821 & 0.051 \\
\hline Seeking medicine & $301(41.2)$ & $221(73.4)$ & $80(26.6)$ & 16.713 & $<0.0001$ \\
\hline \multicolumn{4}{|c|}{ Whether doctors were satisfied with types of patients they treated } & 49.153 & $<0.0001$ \\
\hline Satisfied & $374(51.2)$ & $198(52.9)$ & $176(47.1)$ & & \\
\hline Not satisfied & $241(33.0)$ & $192(79.7)$ & $49(20.3)$ & & \\
\hline Hard to say & $115(15.8)$ & $83(72.2)$ & $32(27.8)$ & & \\
\hline \multicolumn{6}{|c|}{ Which types of patients doctors expected (MCQ) } \\
\hline Chronic diseases & $267(36.6)$ & $162(60.7)$ & 105 (39.3) & 3.133 & 0.077 \\
\hline Rare diseases & $338(46.3)$ & $224(66.3)$ & $114(33.7)$ & 0.603 & 0.438 \\
\hline Common diseases & $380(52.1)$ & $228(60.0)$ & $152(40.0)$ & 7.987 & 0.005 \\
\hline Acute diseases & $196(26.8)$ & $143(73.0)$ & $53(27.0)$ & 7.830 & 0.005 \\
\hline Difficult-to-diagnose diseases & $460(63.0)$ & $305(66.3)$ & $155(33.7)$ & 1.243 & 0.265 \\
\hline Rehabilitation & $69(9.5)$ & $43(62.3)$ & $26(37.7)$ & 0.205 & 0.651 \\
\hline Serious diseases & $348(47.7)$ & $238(68.4)$ & $110(31.6)$ & 3.770 & 0.052 \\
\hline Seeking medicine & $62(8.5)$ & $44(71.0)$ & $18(29.0)$ & 1.132 & 0.287 \\
\hline \multicolumn{6}{|c|}{ Which types of patients should seek medical treatment in the community health system (MCQ) } \\
\hline Chronic diseases & $487(66.7)$ & $322(66.1)$ & $165(33.9)$ & 1.125 & 0.289 \\
\hline Rare diseases & $27(3.7)$ & $15(55.6)$ & $12(44.4)$ & 1.049 & 0.306 \\
\hline Common diseases & $556(76.2)$ & $360(64.7)$ & $196(35.3)$ & 0.002 & 0.963 \\
\hline Acute diseases & $33(4.5)$ & $19(57.6)$ & $14(42.4)$ & 0.790 & 0.374 \\
\hline Difficult-to-diagnose diseases & $30(4.1)$ & $23(76.7)$ & $7(23.3)$ & 1.933 & 0.164 \\
\hline Rehabilitation & $368(50.4)$ & $251(68.2)$ & $117(31.8)$ & 3.787 & 0.052 \\
\hline Serious diseases & $23(3.2)$ & $15(65.2)$ & $8(34.8)$ & 0.002 & 0.966 \\
\hline Seeking medicine & $518(71.0)$ & $343(66.2)$ & $175(33.8)$ & 1.580 & 0.209 \\
\hline \multicolumn{4}{|c|}{ Evaluation of patients' medical expenses in tertiary A hospitals } & 8.352 & 0.079 \\
\hline Very cheap & $28(3.8)$ & $24(85.7)$ & $4(14.3)$ & & \\
\hline
\end{tabular}

Continued 


\begin{tabular}{|c|c|c|c|c|c|}
\hline & \multirow[b]{2}{*}{ n (\%) } & \multicolumn{2}{|l|}{ Job satisfaction } & \multirow[b]{2}{*}{$\chi^{2}$} & \multirow[b]{2}{*}{$P$ value } \\
\hline & & $\begin{array}{l}\text { Dissatisfaction n } \\
(\%) \\
473(64.8)\end{array}$ & $\begin{array}{l}\text { Satisfaction } \\
\text { n (\%) } \\
257(35.2)\end{array}$ & & \\
\hline Relatively cheap & $35(4.8)$ & $26(74.3)$ & $9(25.7)$ & & \\
\hline Moderate & $284(38.9)$ & $176(62.0)$ & $108(38.0)$ & & \\
\hline \multicolumn{3}{|c|}{ Evaluation of the extent patients respect doctors } & & 44.764 & $<0.0001$ \\
\hline Not respect & $13(1.8)$ & $11(84.6)$ & $2(15.4)$ & & \\
\hline Relatively not respect & $43(5.9)$ & $36(83.7)$ & $7(16.3)$ & & \\
\hline Moderate & $354(48.5)$ & $260(73.4)$ & $94(26.6)$ & & \\
\hline
\end{tabular}

${ }^{*}$ Participants can choose more than one option in MCQ question. $M C Q$, multiple-choice question.

training places more pressure on young staff, since it requires doctors to do an additional 2-4 years of specialist training after completing 3 years of resident standardisation training. ${ }^{44}$ During this process, young doctors may become unsatisfied with their income and their inability to support their families, which, in turn, promotes further job dissatisfaction.

Second, patient composition was a significant factor influencing doctors' job satisfaction. Around $51.2 \%$ of the doctors were satisfied with the type of patients they treated; however, $52.1 \%$ of the doctors mostly treated patients with common diseases every day. The low satisfaction seemed to reflect the gap between their expectations and the reality. Given that doctors in tertiary A public hospitals have the best professional abilities and hope to deal with the most difficult and complicated diseases, they expect to treat patients with difficult-to-diagnose diseases. However, unlike the two-way referral system in many developed countries (eg, the USA), patients in China can choose the health institution they prefer. ${ }^{45}$ This causes overcrowding in tertiary A public hospitals, ${ }^{46}$ regardless of disease type. In fact, many patients with common, mild, or chronic diseases do not need to visit tertiary A public hospitals, as this wastes high-quality medical resources. Under these circumstances, doctors who wish to solve difficult-to-diagnose cases feel disappointed and dissatisfied with their work. ${ }^{14}$ To solve this problem, hospital patient flow logistics should be controlled. ${ }^{47}$ Encouraging patients and doctors to accept the two-way referral is vital; however, the level of trust between doctors and patients is also critical. Moreover, it should be noted that inadequate time spent treating difficult-to-diagnose diseases has a negative effect on doctors' skill development, which can also cause doctors' job dissatisfaction. Policymakers and hospital administrators should provide more opportunities to doctors expecting more difficult-to-diagnose patients, especially junior doctors.

Third, work stress was related to job satisfaction, which supported a past study. ${ }^{5}$ However, we also found that relative work stress (ie, comparing work stress to that in the past year) more significantly predicted job satisfaction than did present work stress. Doctors who felt greater relative work stress were more likely to be dissatisfied with their job than their counterparts. In addition, the factors that doctors consider as reflective of work stress, especially work intensity and social evaluation, require attention. Doctors working in tertiary A public hospitals usually undertake many clinical tasks; for example, because of the excess of patients, doctors have to diagnose and treat them as fast as possible, which limits doctors' ability to take breaks. ${ }^{48}$ Moreover, several doctors have been reported to die suddenly, possibly because of the work intensity. ${ }^{49}$ Similar studies in other countries have also stated that work intensity negatively affects job satisfaction. ${ }^{14} 38$ Moreover, improving their social evaluation may improve doctors' job satisfaction. At present, doctors in China do not have a good reputation because of some doctors pursuing personal economic interests by prescribing unnecessary medicine or tests for patients. ${ }^{50}$ It must be noted that there are many other doctors who do not resort to such unethical practices; however, they also become victims of this stigmatisation. Our society should maintain an objective and impartial attitude towards most doctors and supervise those with a poor reputation.

Fourth, doctors' long work hours require attention. Working overtime has caused low job satisfaction worldwide, such as in Britain, ${ }^{51}$ Spain ${ }^{52}$ and Switzerland. ${ }^{42}$ Our finding was similar. Although the European Working Time Directive ruled that junior doctors should work no more than 48 hours per week, ${ }^{53}$ this was unrealistic in China. 
Table 4 Logistic regression analysis of job satisfaction and its influencing factors

\begin{tabular}{|c|c|c|c|c|c|}
\hline \multirow[b]{2}{*}{ Parameter } & \multirow[b]{2}{*}{ Estimate } & \multirow[b]{2}{*}{$P$ value } & \multirow[b]{2}{*}{ OR } & \multicolumn{2}{|c|}{ 95\% Wald Cl } \\
\hline & & & & Lower limit & Upper limit \\
\hline \multicolumn{6}{|c|}{ Whether doctors were satisfied with types of patients they treated } \\
\hline Satisfied & 0.876 & 0.0007 & 2.401 & 1.447 & 3.982 \\
\hline Not satisfied & -0.244 & 0.408 & 0.784 & 0.440 & 1.397 \\
\hline Hard to say & Ref & Ref & Ref & Ref & Ref \\
\hline \multicolumn{6}{|c|}{ Evaluation of the extent patients respect doctors } \\
\hline Not respect & -1.050 & 0.261 & 0.350 & 0.056 & 2.187 \\
\hline $\begin{array}{l}\text { Relatively not } \\
\text { respect }\end{array}$ & -0.831 & 0.166 & 0.436 & 0.134 & 1.412 \\
\hline Moderate & -0.612 & 0.136 & 0.542 & 0.242 & 1.213 \\
\hline Relatively respect & 0.223 & 0.573 & 1.256 & 0.568 & 2.776 \\
\hline Respect & Ref & Ref & Ref & Ref & Ref \\
\hline \multicolumn{6}{|c|}{ Whether work intensity reflected work stress } \\
\hline No & 0.527 & 0.009 & 1.695 & 1.143 & 2.512 \\
\hline Yes & Ref & Ref & Ref & Ref & Ref \\
\hline \multicolumn{6}{|c|}{ Whether a poor social evaluation reflected work stress } \\
\hline No & 0.813 & 0.0002 & 2.254 & 1.466 & 3.466 \\
\hline Yes & Ref & Ref & Ref & Ref & Ref \\
\hline \multicolumn{6}{|l|}{ Work stress } \\
\hline Very light & - & - & - & - & - \\
\hline Relatively light & 13.763 & 0.986 & $>999.999$ & $<0.001$ & $>999.999$ \\
\hline Moderate & 1.034 & 0.001 & 2.813 & 1.553 & 5.096 \\
\hline Relatively great & 0.061 & 0.763 & 1.063 & 0.714 & 1.584 \\
\hline Very great & Ref & Ref & Ref & Ref & Ref \\
\hline \multicolumn{6}{|c|}{ Whether the work within work hours met hospital requirements } \\
\hline Can & 0.498 & 0.410 & 1.645 & 0.504 & 5.366 \\
\hline Mostly can & 0.788 & 0.187 & 2.198 & 0.683 & 7.080 \\
\hline Mostly cannot & -0.250 & 0.711 & 0.779 & 0.207 & 2.926 \\
\hline Cannot & 0.585 & 0.482 & 1.795 & 0.352 & 9.159 \\
\hline Hard to say & Ref & Ref & Ref & Ref & Ref \\
\hline \multicolumn{6}{|c|}{ Whether working long hours reflected work stress } \\
\hline No & 0.303 & 0.111 & 1.354 & 0.933 & 1.964 \\
\hline Yes & Ref & Ref & Ref & Ref & Ref \\
\hline \multicolumn{6}{|c|}{ Whether patients with common diseases were the population doctors expected } \\
\hline No & -0.415 & 0.025 & 0.660 & 0.459 & 0.945 \\
\hline Yes & Ref & Ref & Ref & Ref & Ref \\
\hline \multicolumn{6}{|c|}{ Whether patients with acute diseases were the population doctors expected } \\
\hline No & 0.360 & 0.084 & 1.434 & 0.953 & 2.158 \\
\hline Yes & Ref & Ref & Ref & Ref & Ref \\
\hline \multicolumn{6}{|l|}{ Professional title } \\
\hline Junior & -0.916 & 0.031 & 0.400 & 0.197 & 0.811 \\
\hline Intermediate & -0.761 & 0.011 & 0.467 & 0.234 & 0.933 \\
\hline Associate senior & -0.723 & 0.031 & 0.485 & 0.230 & 1.022 \\
\hline Senior & Ref & Ref & Ref & Ref & Ref \\
\hline
\end{tabular}


Doctors have to work overtime, which often limits their family time and spare time. However, a study proposed that work-private hours also play a key role in job satisfaction. ${ }^{9}$ In addition, in Chinese hospitals, doctors' payment is based on their performance, indicating that meeting job requirements may be more critical than working long hours. Moreover, performance is critical for promotion, especially for junior doctors. Therefore, there is an urgent need to shorten doctors' weekly work hours and change the current promotion and income structure, which may promote increased job satisfaction. ${ }^{54}$

Fifth, it is reasonable to assume that if doctors feel respected by patients, they will be more satisfied with their work. Respect from patients indicates that their professional abilities, personal characteristics and good reputation are recognised. All of these good aspects would accelerate doctors' enthusiasms of their work, which then reflected as job satisfaction. However, due to the overcrowding of patients in tertiary A public hospitals, patients spend a long time waiting to register, pay and fill prescriptions compared with the short time meeting the doctors. This unreasonable phenomenon has reduced patients' satisfaction and their respect for doctors, and sometimes even results in violence against doctors. ${ }^{55}$ Therefore, experiencing a poor patient-doctor relationship and violence from patients might lead to doctors' job dissatisfaction. To address this concern and improve the patient-doctor relationship, the number of patients visiting tertiary A public hospitals should be decreased. If patients with common or minor diseases are willing and encouraged to seek medical treatment in the community healthcare system, doctors at tertiary A hospitals can spend more time diagnosing, treating and communicating with patients, while maintaining a positive and patient attitude. $^{56}$

Finally, other life stress is also related to job satisfaction, and problems such as depression and burnout require consideration. ${ }^{57}$ Work-family conflict should also be addressed to avoid job dissatisfaction. ${ }^{5}$ Moreover, doctors' professional title and department might factor into their job satisfaction. Junior doctors might experience more life stress due to supporting their families; therefore, these doctors may require additional support. Doctors in different departments may also enjoy various extensions of job satisfaction, ${ }^{21}$ indicating that hospital administrators should improve the working conditions to various degrees according to the doctors' departments.

There are two limitations to this study. First, due to doctors' unwillingness to answer questions about certain personal information, information on age distribution and income were not obtained, which made it impossible to explore the effects of these on job satisfaction. Second, this survey was only conducted in eleven tertiary A public hospitals in Shanghai, which limits generalizability. Future studies should include more hospitals and more possible factors.

\section{CONCLUSIONS}

In conclusion, most doctors were not satisfied with their jobs in Shanghai, China, and this was mainly influenced by their professional title, patient composition and work stress. To address this problem, policymakers and hospital administrators should establish the two-way referral system, improve the current promotion and income structure, pay more attention to less-experienced staff and help doctors release their work stress.

Contributors This manuscript was jointly completed by JL, WY, TD, ML and LZ. We must point out that the four authors-JL, WY, TD and ML-contributed equally to this research. Here are the specific efforts of each author. JL, WY ,TD and ML made substantial contributions to conception and design, analysis and interpretation of data, drafting the manuscript and revising it critically for important intellectual content. LZ made substantial contributions to conception and design. All authors read and gave final approval of the version to be published.

Funding This work was supported by National Natural Science Foundation of China (71233008, 91224005, 71673291, 71303248), Important Disease Joint Research Project in Health Systems of Shanghai (2013ZYJB0006) and Military Health Support Strategy and Key Technology Research for Special Injuries in the South China Sea Region (AWS12J002).

Competing interests None declared.

Patient consent for publication Obtained.

Ethics approval Ethics Committee of the Second Military Medical University. Provenance and peer review Not commissioned; externally peer reviewed. Data sharing statement № additional data are available.

Open access This is an open access article distributed in accordance with the Creative Commons Attribution Non Commercial (CC BY-NC 4.0) license, which permits others to distribute, remix, adapt, build upon this work non-commercially, and license their derivative works on different terms, provided the original work is properly cited, appropriate credit is given, any changes made indicated, and the use is non-commercial. See: http://creativecommons.org/licenses/by-nc/4.0/.

\section{REFERENCES}

1. Cox KB. The effects of intrapersonal, intragroup, and intergroup conflict on team performance effectiveness and work satisfaction. Nurs Adm Q 2003;27:153-63.

2. Tarcan M, Hikmet N, Schooley B, et al. An analysis of the relationship between burnout, socio-demographic and workplace factors and job satisfaction among emergency department health professionals. Appl Nurs Res 2017;34:40-7.

3. Zhou X, Pu J, Zhong X, et al. Burnout, psychological morbidity, job stress, and job satisfaction in Chinese neurologists. Neurology 2017;88:1727-35.

4. Mache S, Baresi L, Bernburg M, et al. Being prepared to work in gynecology medicine: evaluation of an intervention to promote junior gynecologists professionalism, mental health and job satisfaction. Arch Gynecol Obstet 2017;295:153-62

5. Lu Y, Hu XM, Huang XL, et al. Job satisfaction and associated factors among healthcare staff: a cross-sectional study in Guangdong Province, China. BMJ Open 2016;6:e011388.

6. Kvist T, Voutilainen A, Mäntynen R, et al. The relationship between patients' perceptions of care quality and three factors: nursing staff job satisfaction, organizational characteristics and patient age. BMC Health Serv Res 2014;14:466.

7. Krueger P, White D, Meaney C, et al. Predictors of job satisfaction among academic family medicine faculty: findings from a faculty work-life and leadership survey. Can Fam Physician 2017;63:e177-85.

8. Pedrazza M, Berlanda S, Trifiletti E, et al. Exploring physicians' dissatisfaction and work-related stress: development of the phydis scale. Front Psychol 2016;7:1238.

9. Schmit Jongbloed LJ, Cohen-Schotanus J, Borleffs JCC, et al. Physician job satisfaction related to actual and preferred job size. BMC Med Educ 2017;17:86.

10. Suárez M, Asenjo M, Sánchez M. Job satisfaction among emergency department staff. Australas Emerg Nurs J 2017;20:31-6. 
11. Wada K, Arimatsu M, Higashi T, et al. Physician job satisfaction and working conditions in Japan. J Occup Health 2009;51:261-6.

12. Shakir S, Ghazali A, Shah IA, et al. Job satisfaction among doctors working at teaching hospital of Bahawalpur, Pakistan. J Ayub Med Coll Abbottabad 2007;19:81-3.

13. Madaan N. Job satisfaction among doctors in a tertiary care teaching hospital. JK Sci 2008;10:81-3.

14. Waddimba AC, Scribani M, Krupa N, et al. Frequency of satisfaction and dissatisfaction with practice among rural-based, groupemployed physicians and non-physician practitioners. BMC Health Serv Res 2016;16:613.

15. Ritsema TS, Roberts KA. Job satisfaction among British physician associates. Clin Med 2016;16:511-3.

16. Pantenburg B, Kitze K, Luppa M, et al. Job satisfaction of foreignnational physicians working in patient care: a cross-sectional study in Saxony, Germany. J Occup Med Toxicol 2016;11:41.

17. Jaques $\mathrm{H}$. Nearly half of UK young doctors say stress levels rose last year. BMJ 2013;346:1

18. Tsuno K, Kawakami N, Inoue A, et al. Intragroup and intergroup conflict at work, psychological distress, and work engagement in a sample of employees in Japan. Ind Health 2009;47:640-8.

19. Siegle M. Solutions for the violence at medical locations in USA. Chinese Medical Ethics 2014;27:24-6.

20. Chen Q, Yang L, Feng Q, et al. Job satisfaction analysis in rural china: a qualitative study of doctors in a township hospital. Scientifica 2017;2017:1964087-

21. de Oliveira Vasconcelos Filho P, de Souza MR, Elias PE, et al. Physicians' job satisfaction and motivation in a public academic hospital. Hum Resour Health 2016;14:75

22. Frenk J, Chen L, Bhutta ZA, et al. [Health professionals for a new century: transforming education to strengthen health systems in an interdependent world]. Rev Peru Med Exp Salud Publica 2011;28:337-41.

23. Paternotte $\mathrm{E}$, van Dulmen $\mathrm{S}$, van der Lee $\mathrm{N}$, et al. Factors influencing intercultural doctor-patient communication: a realist review. Patient Educ Couns 2015;98:420-45.

24. Bergin E, Johansson H, Bergin R. Are doctors unhappy? A study of residents with an open interview form. Qual Manag Health Care 2004;13:81-7.

25. Adler NE, Boyce T, Chesney MA, et al. Socioeconomic status and health. The challenge of the gradient. Am Psychol 1994;49:15-24.

26. Cienski J. Polish doctors fall out with new government over pay. Lancet 2007;370:2088.

27. Holt E. Doctors in eastern Europe prepare to walk out over pay. Lancet 2010;376:221-2.

28. Clark F. Doctors protest over Moscow health reforms. Lancet 2014;384:1736.

29. Xp L, Hy H, Shi HY. Rethinking on the policy of new medical reform: fruitful achievements or hidden gaps? Negative 2016:37:52-5.

30. Zhou XM, Zhang XH, Hou N, et al. Analysis of compensation model and method in public general hospital after cancelling medicine addition. China Pharmacy 2013;24:1825-7.

31. Wang X, Xu C. Analysis of compensation methods for public hospitals after abolishing "pharmaceutical makeup" in new health care reform. The Chinese Health Service Management 2011;12:889-90.

32. Ministry of Health P. Annual health statistics. 2012.

33. Jingang $A$. Which future for doctors in China? Lancet 2013;382:936-7.

34. Qin X, Li L, Hsieh C-R. Too few doctors or too low wages? Labor supply of health care professionals in China. China Economic Review 2013;24:150-64.

35. Center for Health Statistics and Information. An analysis report of national health services survey in China. Beijing: National Health and Family Planning Commission of the People's Republic of China, 2013.
36. Ferreira J, Fernandes R, Haase R, et al. Minnesota satisfaction questionnaire-short form: estudo de adaptação e validação para a população portuguesa. Psychologica 2009;51:251-81.

37. Gothe H, Köster A-D, Storz P, et al. Job satisfaction among doctors. Dtsch Arzteb/ 2007;104:1394-9.

38. Nassar Junior AP, Azevedo LC. Factors associated with job and personal satisfaction in adult Brazilian intensivists. Rev Bras Ter Intensiva 2016;28:107-13.

39. Starmer AJ, Frintner MP, Freed GL. Work-life balance, burnout, and satisfaction of early career pediatricians. Pediatrics 2016;137:e20153183.

40. Caloyeras JP, Kanter M, Ives N, et al. Physician professional satisfaction and area of clinical practice: evidence from an integrated health care delivery system. Perm J 2016;20:35-41.

41. DXY. A survey of Chinese doctors' payment in 2012-2013. China Health Human Resources 2014;5:74-5.

42. Goetz K, Jossen M, Szecsenyi J, et al. Job satisfaction of primary care physicians in Switzerland: an observational study. Fam Pract 2016;33:498-503.

43. Huang DM, Yin WQ, Qq Y, et al. Comparison of work well-being among physicians in public hospitals before and after the new health reform. Chin J Hosp Adm 2015;3:217-20.

44. Wu LX, Qi L, Li Y. Challenges faced by young Chinese doctors. Lancet 2016;387:1617.

45. Yu W, Li M, Nong X, et al. Practices and attitudes of doctors and patients to downward referral in Shanghai, China. BMJ Open 2017;7:e012565.

46. Tong J, Zhu Y, Jie J, et al. Analysis of current situation of Chinese health care reform by studying emergency overcrowding in a typical Shanghai hospital. Am J Emerg Med 2012;30:1313-8.

47. Villa S, Prenestini A, Giusepi I. A framework to analyze hospital-wide patient flow logistics: evidence from an Italian comparative study. Health Policy 2014;115:196-205.

48. Jiang NJ, Yang LC, Liu JJ. Doctors' difficulties: a survey of Chinese doctors' living condition conducted by DXY and Life Times. Secondary Doctors' difficulties: a survey of Chinese doctors' living condition conducted by DXY and Life Times. 2011 https://wenku. baidu.com/view/d305d0ea19e8b8f67c1cb980.html.

49. Zhou XL. A sudden dealth of a 26-year-old anesthesiologist in Zhejiang, China. secondary a sudden dealth of a 26-year-old anesthesiologist in Zhejiang, China. 2017 http://news.youth.cn/sh/ 201706/t20170629 10193802.htm.

50. Chen ZL. "Four major problems" of the new health care reform: the major problems and countermeasures of health care reform. Cai Zheng Jian Du 2014;33:70-1.

51. McGowan $\mathrm{Y}$, Humphries N, Burke H, et al. Through doctors' eyes: a qualitative study of hospital doctor perspectives on their working conditions. Br J Health Psychol 2013;18:874-91.

52. Moreno-Jiménez B, Gálvez-Herrer M, Rodríguez-Carvajal R, et al. A study of physicians' intention to quit: the role of burnout, commitment and difficult doctor-patient interactions. Psicothema 2012;24:263-70.

53. Kirkman MA, Watkins LD, Kitchen ND, et al. Early years neurosurgical training in the era of the European working time directive. Br J Neurosurg 2013;27:586-9.

54. Lu Y, Hu XM, Huang XL, et al. The relationship between job satisfaction, work stress, work-family conflict, and turnover intention among physicians in Guangdong, China: a cross-sectional study. BMJ Open 2017;7:e014894.

55. Lancet T. Violence against doctors: Why China? Why now? What next? Lancet 2014;383:1013.

56. Li H, Yu W. Enhancing community system in china's recent health reform: an effort to improve equity in essential health care. Health Policy 2011;99:167-73.

57. Celedova L, Cevela R, Ptacek R, et al. P01-517 - Incidence of stress and depression in assessment medicine doctors in the Czech Republic. European Psychiatry 2011;26:521. 